\title{
National Survey of Clinical Pharmacy Practice in Saudi Arabia-2017-2018: Workload Documentation
}

\author{
Yousef Ahmed Alomi*, (D BSc. Pharm, \\ MSc. Clin Pharm, BCPS, BCNSP, DiBA, CDE, \\ Critical Care Clinical Pharmacists, TPN \\ Clinical Pharmacist, Freelancer Business \\ Planner, Content Editor and Data Analyst, \\ Riyadh, Saudi Arabia. \\ Fatimah Al-Doughan, PharmD, Lecturer \\ College of Pharmacy, Pharmacy Practice \\ Department King Faisal University, \\ Alahssa, Saudi Arabia. \\ Sultan Mohammed Al-Jarallah, Head, \\ Ambulatory Care Pharmacy, Oncology \\ and Hematology Clinical Pharmacist, \\ Pharmaceutical Care Department, Security \\ Forces Hospital, Riyadh, Saudi Araia. \\ Yasir Ahmed Ibrahim, PharmD, Head of \\ Pharmacy Practice Department Pharmacy \\ Practice Department College of Clinical \\ Pharmacy, King Faisal University, Alahssa, \\ Saudi Arabia. \\ Adel Mehmas Alragas, Bsc. Pharm, \\ Staff Pharmacist Pharmacy Department \\ Medical City King Saud University, Riyadh, \\ Saudi Arabia. \\ Norah Omar Bin Haidarah, PharmD, \\ Pharmacy Staff Outpatient pharmacy Dr \\ Sulaiman Al-habib Hopsital, Riyadh, Saudi \\ Arabia.
}

\section{Correspondence: \\ Dr. Yousef Ahmed Alomi, BSc. Pharm, MSc. Clin Pharm, BCPS, BCNSP, DiBA, CDE, Critical Care Clinical Pharmacists, TPN Clinical Pharmacist, Freelancer Business Planner, Content Editor and Data Analyst, P.O.BOX 100, Riyadh 11392, Riyadh, Saudi Arabia.}

Phone no: +966504417712

E-mail: yalomi@gmail.com

\section{Received: 04-05-2019;}

Accepted: 19-09-2019.

Copyright: $\odot$ the author(s),publisher and licensee Pharmacology, Toxicology and Biomedical Reports. This is an open-access article distributed under the terms of the Creative Commons Attribution NonCommercial License, which permits unrestricted non-commercial use, distribution, and reproduction in any medium, provided the original work is properly cited.

This is an open access article distributed under the terms of the Creative Commons Attribution-NonCommercial-ShareAlike 4.0 License

Access this article online

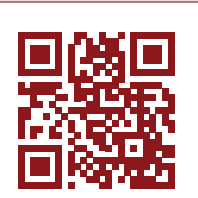

www.ptbreports.org

DOI:

10.5530/PTB.2020.6.16

\begin{abstract}
Objectives: To explore the workload documentation of clinical pharmacy practice in Saudi Arabia during 2017-2018. Methods: This is a 4-month cross-sectional national survey regarding the workload documentation of clinical pharmacy practice in Saudi Arabia. The survey consisted of two parts: The first part collected demographic information and the second part comprised a questionnaire with 51 questions divided into four domains. These domains were derived from the American Society of Health-System Pharmacists (ASHP) and Saudi Pharmaceutical Society (SPS) survey and the International Standard of Joint Commission of Hospital Accreditation in addition to the local standards of Saudi Center of Healthcare Accreditation. The four domains were clinical pharmacy administration and management, performances and activities, education and training and workload documentation. We used 5-point Likert response scale system with close-ended questions to obtain the responses. The questionnaire was distributed in an electronic format to the 31 directors of pharmacies at hospitals. In this study, we conducted a national survey of clinical pharmacy practice at hospitals in Saudi Arabia on workload analysis and documentation. All data were obtained through the Survey Monkey system. Results: The survey was distributed to 31 hospitals and the total number of the patients who were followed up through clinical pharmacy services was 27.88 daily, 836.29 monthly, with 10.82 patients daily per hospital. The total number of prescriptions reviewed by the clinical pharmacist was 184.86 daily, 1294.05 monthly, with (68.77) patients daily per each hospital. Most of the documented clinical pharmacy services existed for medication errors $(80.65 \%)$, adverse drug reactions $(77.42 \%)$ and drug quality reporting $(70.97 \%)$. Most of the documentation of clinical impact and cost avoidance of clinical pharmacy services existed for drug information inquiries (61.29\%), medication errors (58.06\%) and adverse drug reactions $(58.06 \%)$. Most of the monthly workload analysis of clinical activities existed for the number of prescriptions $(80.65 \%)$, number of medication errors $(70.97 \%)$ and for adverse drug reactions $(67.74 \%)$. Conclusion: The documentation of workload of clinical pharmacy services is inadequate especially with respect to the clinical outcome and cost avoidance impact. Most of the clinical pharmacy activities were ordinary performances provided to few numbrer of patients. Improve the documentation of workload activities is highly recommended in Saudi Arabia.
\end{abstract}

Key words: Clinical, Pharmacy, Practice, Workload, Documentation, Saudi Arabia.

\section{INTRODUCTION}

Clinical pharmacists provide a wide range of clinical services in collaboration with other healthcare providers as a team. All these services are aimed to improve the clinical outcome of the patient. ${ }^{1,2}$ Documentation of the clinical activity (workload), clinical interventions and cost avoidance is essential especially with the New Pharmacy Vision 2030 of Saudi Arabia to advocate future growth of resources..$^{3-6}$ Having a clear vision, mission and goals requires consistent documentation of the services to ensure that we are in the right path. ${ }^{7,8}$ Various methods of documentation of clinical pharmacy services has been implemented throughout local and national pharmacy practice programs in the KSA. ${ }^{9-13}$ Documentation and analysis of workload helps to identify obstacles with scheduling, interruptions, priorities and pharmacists' knowledge of clinical pharmacy practice. By knowing and understanding the problems that can reduce documentation, we can overcome such issues in the future. ${ }^{14}$ Previous studies conducted globally have focused on the documentation of workload and analyzing the factors that can reduce or influence the documentation process. ${ }^{15-19}$ To the best of our knowledge, this is the first study to discuss and explore the documentation and analysis of workload of clinical pharmacy services in KSA. ${ }^{4,5} \mathrm{We}$ explored the national survey of clinical pharmacy practice in Saudi Arabia during 2017-2018 with an emphasis on the workload analysis and documentation.

\section{METHODS}

This is a 4-month cross-sectional national survey of clinical pharmacy practice in Saudi Arabia. The survey consists of two parts: The first part collects demographic information and the second part comprises of 51 questions divided into four domains. The questionnaire is adopted from the American Society of Health-System Pharmacists (ASHP) and Saudi Pharmaceutical Society (SPS) survey, the international standards of Joint Commission of Hospital Accreditation, in addition to the local standards of Saudi Center of Healthcare Accreditation. ${ }^{15,16,20-36}$ The domains were clinical pharmacy administration and management, performances and activities, education and training and workload documentation. We used a 5-point Likert response scale system with 
close-ended questions to obtain responses. The questionnaire was distributed in an electronic format to 31 directors of pharmacies at various hospitals in Saudi Arabia. The patients were followed-up by an email and telephone after every 1-2 weeks. All primary healthcare centers and regional pharmacy administration at $\mathrm{MOH}$ were excluded from this study. In this study, we discussed and analyzed the national survey of clinical pharmacy practice at hospitals in Saudi Arabia with a focus on workload analysis and documentation. All data were analyzed through the Survey Monkey system and analyzed using Statistical Package of Social Sciences (SPSS) version 20 . The data were validated via three methods of validation and more than two authors reviewed the data independently. The pilot study was conducted and then the survey data were cleaned. Finally, we calculated the Cronbach's alpha value for internal validity. This survey was exempted from the international guidelines of institutional review boards (IRB). ${ }^{37}$

\section{RESULTS}

The survey was distributed to 31 hospitals. Of them, 7 (22.58\%) hospitals consisted of 200-299 beds, whereas 6 (19.35\%) hospitals had 300-299 beds followed by 5 (16.13\%) hospitals with $50-99$ beds and 5 (16.13\%) hospitals with 400-499 beds. Of the total 31 hospitals, 19 (67.86\%) were accredited by CBAHI, 5 (17.86\%) were accredited by the Saudi Commission of Health Specialties and $4(14.29 \%)$ were accredited by the Joint Commission. Majority of the hospitals (23 (74.19\%)) covered $<25 \%$ of the patients through health insurance. Most of the responders had Bachelor of Science in Pharmacy degree (13 (41.94\%)), whereas only 9 pharmacists had a Doctor of Pharmacy degree $(29.03 \%)$. However, all pharmacists (100\%) were not certified by the BPS. Most of the responders had $1-3$ years $(32.26 \%)$ of experience, whereas $22.58 \%$ of the responders had 4-6 years of experience (Table 1). The total number of patients followed up through clinical pharmacy services were 27.88 daily, 836.29 monthly, with 10.82 patients daily followed up per hospital. While the total number of prescriptions reviewed by the clinical pharmacists were 184.86 daily, 1294.05 monthly, with 68.77 prescriptions followed up daily per hospital (Table 2). Most of the clinical pharmacy services that were documented were for medication errors (80.65\%) followed by ADRs (77.42\%) and drug quality reporting (70.97\%). The hospitals documented clinical pharmacy services either manually or electronically. A total of $18(58.06 \%)$ medication errors were documented manually and 11 (35.48\%) were documented electronically; 18 (58.06\%) ADRs were documented manually and 9 (29.03\%) ADRs were documented electronically. Next, 16 (51.61\%) reports of drug quality were documented manually and 9 (29.03\%) reports were documented electronically (Table 3 ). The most documented clinical pharmacy services of clinical impact and cost avoidance were recorded for drug information inquiries $(61.29 \%)$, medication errors (58.06\%) and ADRs (58.06\%). In the case of adult patients, the most common documented clinical pharmacy services of clinical impact and cost avoidance was for drug information inquiries (19 (61.29\%)), medication errors (18 (58.06\%)) and ADRs (18 (58.06\%)), whereas in the case of pediatric patients, 13 (41.94\%) medication errors, $12(38.71 \%)$ drug information inquiries and 10 (33.33\%) pharmacist intervention were recorded. In the case of neonate patients, drug information inquiries was the most recorded category $(10$ (32.26\%)) followed by medication errors $(8(25.81 \%))$ and poisoning information inquiries $(7$ $(25.81 \%)$ ) (Table 4$)$. The monthly workload of clinical pharmacy services of clinical activities was recorded for prescriptions (80.65\%), number of medication errors (70.97\%) and ADRs (67.74\%). The most documented clinical pharmacy monthly workload analysis of clinical activities in adult patients is the number of prescriptions $(24(77.42 \%))$ followed by the medication errors $(21(67.74 \%))$ and ADRs $(21(67.74 \%))$, whereas in the case of pediatric patients, the number of prescriptions (18 (58.06\%)) was the most commonly documented clinical activity followed by the number of medication errors $(14(45.16 \%))$ and the number of ADRs $(14(45.16 \%))$. In the case of neonate patients, the number of prescriptions (13 (41.94\%)) was the most commonly documented clinical activity, followed by the number of patients $(11(36.67 \%))$ and the number of medication errors ( $9(29.03 \%))$ (Table 5). Cronbach's alpha value was found to be 0.765 .

\section{DISCUSSION}

The analysis of workload documentation is very important for all healthcare professionals. Clinical pharmacy services measure the current level of patient care and its analysis helps to plan for the future expansion as it serves as an evidence of the progress done by pharmacists on the impact of patient care outcome and cost. In our study, medication errors was the most documented clinical service as it is one of the common intervention pharmacists provide. ${ }^{38}$ The majority of the documentation was done manually despite that electronic documentation is available. This result can raise many questions. Why did pharmacists not use the electronic documentation? Is it complicated? What are the factors that withhold pharmacists from using electronic documentation? Manual documentation is considered as one of the obstacles for pharmacists as it is a timeconsuming process and it is at greater risk as the documents might be lost and be left incomplete. ${ }^{7}$ Many studies have shown the benefit of using a computerized system to document the clinical services as it makes the process easier and saves time in addition to that using a computerized system can make the documented data very useful by the ability to generate different analysis in order to provide useful reports that increased cost avoidance. ${ }^{7,19,39,40}$ However, drug information inquiries were found to be the most documented clinical service in this study that has a clinical impact and cost avoidance role to it, especially for adult and neonate patients. ${ }^{4,5}$ The previous study has shown that documentation of drug information inquiries helps to calculate the increase in cost avoidance and measures the impact of pharmacists. ${ }^{41}$ In previous study, workload documentation analysis did not yield positive results and some of the participants considered it as not necessary and may lead to deprived pharmacist's time for patient care..$^{42}$ In this study, we obtained $50 \%$ as the average percentage of workload analysis. Compared to the other clinical activities, the number of prescriptions was the most documented clinical activity in the monthly workload analysis in all patient groups. This might be because the number of prescriptions and dispensing were the most comfortable and most accurate clinical activity to be measured especially with the use of a computerized dispensing system..$^{42}$ The documentation of clinical pharmacy services workload is meager especially with respect to two essential points: clinical outcomes and cost avoidance. Without documentation, we cannot attain the required information needed for determining the clinical outcomes and cost avoidance. We need to study the factors that prohibited pharmacists from taking up documentation. Many factors mentioned in previous studies show that pharmacists get discouraged from the process of documentation. First, documentation is a time-consuming process especially if it is done manually and requires tabulation of the data. Inaccuracy, duplication of the data and inconsistency were also mentioned. ${ }^{7,42,43}$ However, many factors found to influence the documentation process. The pharmacist who has a positive professional attitude along with high clinical knowledge and a high level of training on the use of electronic documentation tend to have a high intervention rate. ${ }^{38}$

\section{CONCLUSION}

The documentation of workload of clinical pharmacy services was found to be inadequate in this study, especially in the cost avoidance and clinical outcome impact. There is a need to study the factors that can discourage pharmacists from documentation in order to improve the workload 


\begin{tabular}{|c|c|c|c|c|c|}
\hline No. of hospital licensed & Response $\mathrm{N}$ & Response \% & Response N & Response \% & Response $\mathrm{N}$ \\
\hline$<50$ & 3 & $9.68 \%$ & Diploma. Pharmacy & 3 & $9.68 \%$ \\
\hline 100-199 & 2 & $6.45 \%$ & Master of Science & 7 & $22.58 \%$ \\
\hline 200-299 & 7 & $22.58 \%$ & Doctor of Pharmacy & 9 & $29.03 \%$ \\
\hline $400-499$ & 5 & $16.13 \%$ & Three years Residency (R2) & 1 & $3.23 \%$ \\
\hline$=$ or $>600$ & 1 & $3.23 \%$ & $\mathrm{Ph} . \mathrm{D}$ & 1 & $3.23 \%$ \\
\hline Medical City & 2 & $6.45 \%$ & M.B.A. & 0 & $0.00 \%$ \\
\hline Answered question & 31 & & Answered question & 31 & $0.95 \%$ \\
\hline CBAHI & 19 & $67.86 \%$ & $\begin{array}{l}\text { Board Certified Ambulatory Care } \\
\text { Pharmacist }\end{array}$ & 0 & $0.00 \%$ \\
\hline Joint Commotion USA & 4 & $14.29 \%$ & $\begin{array}{l}\text { Board Certified Critical Care } \\
\text { Pharmacist }\end{array}$ & 0 & $0.00 \%$ \\
\hline Canada & 0 & $0.00 \%$ & $\begin{array}{l}\text { Board Certified Nuclear } \\
\text { Pharmacist }\end{array}$ & 0 & $0.00 \%$ \\
\hline Saudi Council & 5 & $17.86 \%$ & $\begin{array}{l}\text { Board Certified Nutrition Support } \\
\text { Pharmacist }\end{array}$ & 0 & $0.00 \%$ \\
\hline None & 0 & $\begin{array}{c}00.00 \% \\
14.29 \% \\
0.00 \% \\
17.86 \%\end{array}$ & $\begin{array}{l}\text { Board Certified Oncology } \\
\text { Pharmacist }\end{array}$ & 0 & $0.00 \%$ \\
\hline$<25 \%$ & 23 & $74.19 \%$ & Non & 31 & $100.00 \%$ \\
\hline $25-50 \%$ & 3 & $9.68 \%$ & Answeredquestion & 31 & \\
\hline $51-75 \%$ & 3 & $9.68 \%$ & Skipped question & 0 & \\
\hline $76-100 \%$ of our patients. & 2 & $6.45 \%$ & $\begin{array}{l}\text { Years of Experiences in Clinical } \\
\text { Pharmacy }\end{array}$ & Response N & Response \% \\
\hline Answered & 31 & & $<1$ & 3 & $9.68 \%$ \\
\hline \multirow[t]{3}{*}{ Skipped } & 0 & & $1-3$ & 10 & $32.26 \%$ \\
\hline & & & $4-6$ & 7 & $22.58 \%$ \\
\hline & & & $>6$ & 3 & $9.68 \%$ \\
\hline \multicolumn{4}{|l|}{ Answered question } & 31 & \\
\hline \multicolumn{4}{|l|}{ Skipped question } & 0 & \\
\hline
\end{tabular}

activities documentation in the KSA in order to benefit from the positivity of documenting clinical pharmacy services.

\section{ACKNOWLEDGEMENT}

None.

\section{CONFLICT OF INTEREST}

The authors declare conflict of interest.

\section{ABBREVIATIONS}

ASHP: American Society of Health-System Pharmacists; ADRs: Adverse drug reactions; BPS: Board of Pharmaceutical Specialties; CBAHI: 


\begin{tabular}{|c|c|c|c|c|c|c|c|c|c|c|}
\hline \multicolumn{6}{|c|}{ No of Patients Monthly Provides clinical pharmacy services } & \multicolumn{5}{|c|}{ No of weekly Prescriptions reviewed by clinical pharmacist } \\
\hline 1 & 13 & $41.94 \%$ & $\begin{array}{c}\text { Monthly } \\
21.45\end{array}$ & $\begin{array}{l}\text { daily } \\
21.45\end{array}$ & $\begin{array}{c}\begin{array}{c}\text { Daily per } \\
\text { hospital }\end{array} \\
1.65\end{array}$ & 6 & $19.35 \%$ & $\begin{array}{l}\text { weekly } \\
297.00\end{array}$ & $\begin{array}{l}\text { daily } \\
42.43\end{array}$ & $\begin{array}{c}\text { Daily per hospital } \\
7.07\end{array}$ \\
\hline 4 & 2 & $6.45 \%$ & 23.30 & 23.30 & 11.65 & 3 & $9.68 \%$ & $1,048.50$ & 149.79 & 49.93 \\
\hline 5 & 0 & $0.00 \%$ & 0.00 & 0.00 & 0.00 & 4 & $12.90 \%$ & $1,798.00$ & 256.86 & 64.21 \\
\hline 6 & 1 & $3.23 \%$ & 18.32 & 18.32 & 18.32 & 1 & $3.23 \%$ & 549.50 & 78.50 & 78.50 \\
\hline 7 & 1 & $3.23 \%$ & 21.65 & 21.65 & 21.65 & 0 & $0.00 \%$ & 0.00 & 0.00 & 0.00 \\
\hline 10 & 2 & $6.45 \%$ & 63.30 & 63.30 & 31.65 & 2 & $6.45 \%$ & $1,899.00$ & 271.29 & 135.64 \\
\hline 11 & 5 & $16.13 \%$ & 158.25 & 158.25 & 31.65 & 6 & $19.35 \%$ & $5,697.00$ & 813.86 & 135.64 \\
\hline 12 & 2 & $6.45 \%$ & 0.00 & 0.00 & 0.00 & 0 & $0.00 \%$ & 0.00 & 0.00 & 0.00 \\
\hline Average & & & 836.29 & 27.88 & 10.82 & & & $1,294.05$ & 184.86 & 68.77 \\
\hline
\end{tabular}

\begin{tabular}{|l|c|c|c|c|c|c|c|c|}
\hline Table 3: Documentation of clinical activities at clinical pharmacy. \\
\hline Answer Options & Yes manually & Yes Electronically & \multicolumn{3}{|c|}{ No } & Percent Existed & Response N \\
\hline Medication errors & 18 & $58.06 \%$ & 11 & $35.48 \%$ & 6 & $19.35 \%$ & $80.65 \%$ & 31 \\
\hline Adverse drug reactions & 18 & $58.06 \%$ & 9 & $29.03 \%$ & 7 & $22.58 \%$ & $77.42 \%$ & 31 \\
\hline Drug quality reporting & 16 & $51.61 \%$ & 9 & $29.03 \%$ & 9 & $29.03 \%$ & $70.97 \%$ & 31 \\
\hline Patient counseling & 12 & $38.71 \%$ & 7 & $22.58 \%$ & 15 & $48.39 \%$ & $51.61 \%$ & 31 \\
\hline Pharmacist intervention & 16 & $51.61 \%$ & 9 & $29.03 \%$ & 10 & $32.26 \%$ & $67.74 \%$ & 31 \\
\hline Drug information inquiries & 15 & $48.39 \%$ & 9 & $29.03 \%$ & 10 & $32.26 \%$ & $67.74 \%$ & 31 \\
\hline Poisoning information inquiries & 13 & $41.94 \%$ & 8 & $25.81 \%$ & 13 & $41.94 \%$ & $58.06 \%$ & 31 \\
\hline Answered & & & & & & & 31 \\
\hline Skipped & & & & & & & \\
\hline
\end{tabular}

Table 4: The documentation of clinical impact and cost avoidance of clinical pharmacy services.

\begin{tabular}{|c|c|c|c|c|c|c|c|c|c|c|}
\hline Answer Options & \multicolumn{2}{|c|}{ Adults } & \multicolumn{2}{|c|}{ Pediatrics } & \multicolumn{2}{|c|}{ Neonates } & \multicolumn{2}{|c|}{ Never } & \multirow{2}{*}{$\begin{array}{c}\text { Percent } \\
\text { Existed }\end{array}$} & \multirow{2}{*}{$\begin{array}{c}\text { Response } \mathrm{N} \\
31\end{array}$} \\
\hline Medication errors & 18 & $58.06 \%$ & 13 & $41.94 \%$ & 8 & $25.81 \%$ & 13 & $41.94 \%$ & & \\
\hline Adverse drug reactions & 18 & $58.06 \%$ & 9 & $29.03 \%$ & 6 & $19.35 \%$ & 13 & $41.94 \%$ & $58.06 \%$ & 31 \\
\hline Drug quality reporting & 15 & $48.39 \%$ & 9 & $29.03 \%$ & 5 & $16.13 \%$ & 15 & $48.39 \%$ & $51.61 \%$ & 31 \\
\hline Patient counseling & 12 & $40.00 \%$ & 9 & $30.00 \%$ & 4 & $13.33 \%$ & 17 & $56.67 \%$ & $43.33 \%$ & 30 \\
\hline Pharmacist intervention & 15 & $50.00 \%$ & 10 & $33.33 \%$ & 5 & $16.67 \%$ & 15 & $50.00 \%$ & $50.00 \%$ & 30 \\
\hline Drug information inquiries & 19 & $61.29 \%$ & 12 & $38.71 \%$ & 10 & $32.26 \%$ & 12 & $38.71 \%$ & $61.29 \%$ & 31 \\
\hline Poisoning information inquiries & 14 & $45.16 \%$ & 10 & $32.26 \%$ & 7 & $22.58 \%$ & 17 & $54.84 \%$ & $45.16 \%$ & 31 \\
\hline Answered & & & & & & & & & & 31 \\
\hline Skipped & & & & & & & & & & 0 \\
\hline
\end{tabular}




\begin{tabular}{|c|c|c|c|c|c|c|c|c|c|}
\hline \multicolumn{2}{|c|}{ Adults } & \multicolumn{2}{|c|}{ Pediatrics } & \multicolumn{2}{|c|}{ Neonates } & \multicolumn{2}{|c|}{ Never } & \multirow{2}{*}{$\begin{array}{l}\begin{array}{l}\text { Percent } \\
\text { Existed }\end{array} \\
70.97 \% \\
\end{array}$} & \multirow{2}{*}{$\begin{array}{c}\text { Response N } \\
31\end{array}$} \\
\hline 21 & $67.74 \%$ & 14 & $45.16 \%$ & 9 & $29.03 \%$ & 9 & $29.03 \%$ & & \\
\hline 21 & $67.74 \%$ & 14 & $45.16 \%$ & 8 & $25.81 \%$ & 10 & $32.26 \%$ & $67.74 \%$ & 31 \\
\hline 17 & $56.67 \%$ & 8 & $26.67 \%$ & 5 & $16.67 \%$ & 13 & $43.33 \%$ & $56.67 \%$ & 30 \\
\hline 17 & $54.84 \%$ & 11 & $35.48 \%$ & 8 & $25.81 \%$ & 15 & $48.39 \%$ & $51.61 \%$ & 31 \\
\hline 14 & $45.16 \%$ & 8 & $25.81 \%$ & 6 & $19.35 \%$ & 17 & $54.84 \%$ & $45.16 \%$ & 31 \\
\hline 20 & $66.67 \%$ & 14 & $46.67 \%$ & 11 & $36.67 \%$ & 10 & $33.33 \%$ & $66.67 \%$ & 30 \\
\hline & & & & & & & & & 31 \\
\hline & & & & & & & & & 0 \\
\hline
\end{tabular}

Saudi Central Board for Healthcare Accreditation; FDA: United States Food and Drug Administration; SFDA: Saudi Food and Drug Authority; KSA: Kingdom of Saudi Arabia; MOH: Ministry of Health; IRB: Institutional Review Board; SPS: Saudi Pharmaceutical Society.

\section{REFERENCES}

1. Pharmacy C, Process I. Standards of practice for clinical pharmacists. Pharmacotherapy. 2014;34(8):794-7.

2. Bright JM, Tenni PC. The Clinical Services Documentation (CSD) System for Documenting Clinical Pharmacists' Services. Aust J Hosp Pharm. 2000;30(1):10-5.

3. Alomi YA, Alghamdi SJ, Alattyh RA, Elshenawy RA. The Evaluation of Pharmacy Strategic Plan in Past 2013-2016 and Forecasting of New Vision 2030 at Ministry of Health in Saudi Arabia. J Pharm Pract Community Med. 2018;4(2):93-101.

4. Alomi YA, Alghamdi SJ, Alattyh RA. National Workload Analysis of Network of Drug Information Centers at Ministry of Health Hospitals in Saudi Arabia. Int J Pharmacol Clin Sci. 2018;7(4):17-25.

5. AlomiYA, Aldosary BA. Cost Analysis of Activities for Network Drug Information Centers at the Ministry of Health Hospitals in Saudi Arabia. Int J Pharm Heal Sci. 2019;2(1):45-51.

6. Nurgat ZA, Al-Jazairi AS, Abu-Shraie N, Al-Jedai A. Documenting clinical pharmacist intervention before and after the introduction of a web-based tool. Int $J$ Clin Pharm. 2011;33(2):200-7.

7. Zimmerman CR, Smolarek RT, Stevenson JG. A Computerized System to Improve Documentation and Reporting of Pharmacists' Clinical Interventions, Cost Savings and Workload Activities. Pharmacother J Hum Pharmacol Drug Ther. 1995;15(2):220-7.

8. Parrish R. Lecture 3-Measuring Pharmacy's Work in the $21^{\text {st }}$ Century. Pharmacy. 2018;6(3):63.

9. Alomi YA. National Pharmacy Administration Programs at Ministry of Health in Saudi Arabia. BAOJ Pharm Sci. 2015;1(9):2

10. Alomi YA, Kamal E. National Drug Quality Reporting System at Ministry of Health in Saudi Arabia. J Pharmacovigil. 2016;4(208):2.

11. Alomi YA, Alghamdi SJ, Alattyh RA. National Pharmacist Intervention Documentation System at the Ministry of Health in Saudi Arabia. Pharmacol Toxicol Biomed Reports. 2019;4(3):31-3.

12. Alomi YA, Alghamdi SJ, Alattyh RA. National Adverse Drug Reaction Reporting System at the Ministry of Health, Saudi Arabia. Pharmacol Toxicol Biomed Reports. 2019;4(3):21-3.

13. Alomi YA, Alghamdi SJ, Alattyh RA. National Medication Errors Reporting System at Ministry of Health in Saudi Arabia. Pharmacol Toxicol Biomed Reports. 2019;5(1):4-7.

14. Hatfield SM, Alessi LS, Brown TN, Rehder TL. Documenting workload to better integrate clinical and distributive services. Am J Heal Pharm. 1985;42(10):21759.

15. Pedersen CA, Schneider PJ, Scheckelhoff DJ. ASHP national survey of pharmacy practice in hospital settings: Monitoring and patient education: 2015. Am J Heal Pharm. 2016;73(17):1307-30.
16. Pedersen CA, Schneider PJ, Scheckelhoff DJ. ASHP national survey of phar macy practice in hospital settings: Prescribing and transcribing: 2016. Am J Heal Pharm. 2017;74(17):1336-52.

17. Maes KA, Studer H, Berger J, Hersberger KE, Lampert ML. Documentation of pharmaceutical care: Validation of an intervention oriented classification system. J Eval Clin Pract. 2017;23(6):1425-32

18. Raybardhan S, Balen RM, Partovi N, Loewen P, Liu G, Jewesson PJ. Documenting drug-related problems with personal digital assistance in a multisite health system. Am J Heal Pharm. 2005;62(17):1782-7.

19. Fox BI, Felkey BG, Berger BA, Krueger KP, Rainer RK. Use of personal digital assistants for documentation of pharmacists' interventions: A literature review. Am J Heal Pharm. 2007;64(14):1516-25.

20. Pedersen CA, Schneider PJ, Scheckelhoff DJ. ASHP national survey of phar macy practice in hospital settings: Dispensing and administration: 2014. Am J Heal Pharm. 2015;72(13):1119-37.

21. Ahmed AY, Jamaan AS, Abdullah AR, Shorog E, Alshahran A, Alasmary S, et al. National Survey of Pharmacy Practice at MOH Hospitals in Saudi Arabia 20162017: Pharmacy Management and Resource. J Pharm Pract Community Med. 2018;4(1s):s1-16.

22. Alomi YA, Alghamdi SJ, Alattyh RA, Shorog E, Alshahran A, Alasmary S, et al. National Survey of Pharmacy Practice At Ministry of Health Hospitals in Saudi Arabia 2016-2017: Prescribing and Medication Management. J Pharm Pr Community Med. 2018;(5):S54-9

23. Alomi YA, Jamaan AS, Abdullah AR, Shorog E, Alshahran A, Alasmary S, et al. National Survey of Pharmacy Practice at MOH Hospitals in Saudi Arabia 20162017: Preparation of Medications and Dispensing. J Pharm Pract Community Med. 2018;4(1s):s54-9.

24. Alomi YA, Shorog E, Alshahrani A, Alasmary S, Alenazi H, Almutairi A, et al. National Survey of Pharmacy Practice at MOH Hospitals in Saudi Arabia 20162017: Drug Monitoring and Patients Education. J Pharm Pract Community Med. 2018;4(1s):s17-22.

25. Alomi YA, Alghamdi SJ, Alattyh RA. National Survey of Pharmacy Practice at MOH Hospitals in Saudi Arabia 2016-2017: Clinical Pharmacy Services. J Pharm Pr Community Med. 2018;4(1):1S-8S.

26. Yousef AA, Saeed JARAA. National Survey of Pharmacy Practice at $\mathrm{MOH}$ Hospitals in Saudi Arabia 2016-2017: Pharmacy Education and Training. J Pharm Pr Community Med. 2018;4(1):1S-8S.

27. Yousef AA, Saeed JARAA. National Survey of Pharmacy Practice at $\mathrm{MOH}$ Hospitals in Saudi Arabia 2016-2017: Pharmacy Inventory Control and Stock Management. J Pharm Pr Community Med. 2018;4(1):S28-33.

28. Alomi YA, Alghamdi SJ, Alattyh RA. National Survey of Pharmacy Practice at MOH Hospitals in Saudi Arabia 2016-2017: Pharmacy Computerized and Technology. J Pharm Pract Community Med. 2018;4(1s):s40-6.

29. Ahmed AY, Jamaan AS, Abdullah AR, Shorog E, Alshahran A, Alasmary S, et al. National Survey of Pharmacy Practice at MOH Hospitals in Saudi Arabia 20162017: Prescribing and Medication Management. J Pharm Pract Community Med. 2018;4(1s):s34-9.

30. Cotter SM, Barber ND, McKee M. Survey of clinical pharmacy services in United Kingdom National Health Service hospitals. Am J Hosp Pharm. 1994;51(21):2676-84. 
31. Čufar A, Mrhar A, Robnik-Šikonja M. Assessment of surveys for the management of hospital clinical pharmacy services. Artif Intell Med. 2015;64(2):147-58.

32. Lanier C, Moss J, Tunney R, Baird R, Kelly K. Clinical Pharmacy Practice Patterns Among North Carolina Rural Hospitals. J Pharm Pract. 2019;89719001986632.

33. Cillis M, Spinewine A, Krug B, Quennery S, Wouters D, Dalleur O. Development of a tool for benchmarking of clinical pharmacy activities. Int J Clin Pharm. 2018;40(6):1462-73

34. Bond CA, Raehl CL, Patry R. Evidence-Based Core Clinical Pharmacy Services in United States Hospitals in 2020: Services and Staffing. Pharmacotherapy. 2004;24(4):427-40

35. CIBAHI. Medication Management. In: National Accreditation Standred. $2^{\text {nd }}$ Edition. Saudi Central Board for Accreditation of Healthcare Institutions. 2016. Available from: http://insights.ovid.com/crossref?an=01222928-201713010-00016

36. The Joint Commission. 2016 Comprehensive Accreditation Manuals. Joint Commission Resources. 2016.

37. The Office for Human Research Protections. Human Subject Regulations Decision Charts. Chart. 2016 [cited 2019 Nov 4]. Available from: https://www.hhs. gov/ohrp/regulations-and-policy/decision-charts/index.html

38. Williams M, Hons B. Factors influencing the performance and documentation of clinical interventions by Australian community pharmacists. 2013. Available from: https://eprints.utas.edu.au/17614/1/Whole-Williams-_thesis.pdf.

39. Mason RN, Pugh CB, Boyer SB, Stiening KK. Computerized documentation of pharmacists' interventions. Am J Heal Pharm. 1994;51(17):2131-8.

40. Huntress JD, Possidente CJ, Harry DJ. Documenting pharmacists' interventions on a hospital's mainframe computer system. Am J Heal Pharm. 1990;47(12):2711-5.

41. Alomi1 YA, Almudaiheem HY. Cost Efficiency of National Drug Information Center Services Through Ministry of Health Hotline Calling Center (937) in Saud Arabia. Int J Pharm Heal Sci. 2019;2(1):17-20.

42. Ng K, Goh SF, Koller LJ. Workload Measurement Practice in Australian Hospital Pharmacy Departments. Aust J Hosp Pharm. 2016;27(4):307-12

43. Bajcar J, Chin T, Chui W, Wichman K. Development of a comprehensive clinical pharmacy workload documentation system. Can J Hosp Pharm. 1995;48(2):80 